ANNALS OF “DUNAREA DE JOS” UNIVERSITY OF GALATI

MATHEMATICS, PHYSICS, THEORETICAL MECHANICS

FASCICLE II, YEAR XIII (XLIV) 2021, No. 1

DOI: https://doi.org/10.35219/ann-ugal-math-phys-mec.2021.1.02

\title{
MANAGEMENT OF NUCLEAR MATERIALS CONTAINING NATURAL URANIUM AND THORIUM SALTS
}

\author{
Florin Sloată ${ }^{1,2,3 *}$, Antoaneta Ene $e^{1,3,4}$ \\ ${ }^{I}$ Dunarea de Jos University of Galati, Doctoral School of Mechanical and Industrial Engineering, 47 \\ Domneasca Street, 800008 Galati, Romania \\ ${ }^{2}$ SETCAR S.A., 6 Gradinii Publice St., 810022 Braila, Romania \\ ${ }^{3}$ INPOLDE interdisciplinary research network, ReForm-UDJG Platform, Dunarea de Jos University of Galati, \\ 111 Domneasca St., 800201 Galati, Romania \\ ${ }^{4}$ Dunarea de Jos University of Galati, Faculty of Sciences and Environment, Department of Chemistry, Physics \\ and Environment, 47 Domneasca Street, 800008 Galati, Romania
}

\begin{abstract}
This paper highlights an experimental model proposed for the management of nuclear materials containing natural uranium and thorium salts, based on technical and legislative methods. The investigated nuclear materials originate from laboratory chemicals with expired validity, having as manufacturers companies specialized in the manufacture of laboratory substances such as: Merck, Chemapol, Sigma Aldrich, Bucharest Reagent. The experimental program refers to several issues of great importance in the waste and environmental management, such as: a) the processing of radioactive substances containing nuclear materials and radioactive waste represented by solid objects contaminated with radionuclides from the radioactive series of U-238 and Th-232; b) gamma dose rate measurement during handling and processing of open sources of ionized radiation; c) measurement of suspicious contamination of the operating personnel which handles the equipment, including the materials used in the processing of open sources of ionizing radiation; and d) the inventory of nuclear materials according to the chemical formula, the mass of chemical substance, the mass of the nuclear element in each container and type of packaging. For the good development of processing these open sources of ionizing radiation containing nuclear materials, the ALARA principle (As Low As Reasonably Achievable) was applied, which is fundamental to the principles of radiation protection. All the measurements for determining the gamma dose rate and suspicious contamination were performed with the aid of a CoMo 170 radiometric device produced by Nuvia Instruments Gmbh Germany, equipped with a 170x100 m² PL detector with zinc sulfide calibrated with the aid of C-14, Co-60, Cs-137, U-238 and Am-241 radioactive isotopes and an external probe containing a scintillating crystal with sodium iodide enriched with thallium calibrated with Cs- 137 .
\end{abstract}

Keywords: nuclear materials, natural uranium, thorium, radiological measurements, radioprotection.

\section{INTRODUCTION}

The subject of "Nuclear Materials" appeared in the 1950s and began to develop as an internationally recognized field. The beginning of this field was attributed to the presentations and discussions that took place at the first and second international conferences on the peaceful use of atomic energy which took place in Geneva in 1955 and 1958. The Journal of Nuclear Materials, founded in 1959, is the journal of origin for this field for materials science [1]. Nuclear materials pose a real threat if used in the manufacture of nuclear bombs or conventional dirty bombs. Nuclear bombs can be made of highly enriched plutonium or uranium. Plutonium is obtained in plants that reprocess spent fuel waste from conventional reactors, the natural contain the fissile isotope U-235 to a maximum of $0.7 \%$ [2]. 
Nuclear safeguards control covers protection against the misuse of nuclear installations and the diversion of nuclear materials from peaceful uses. Physical protection is about ensuring the health, safety, and well-being of people at work, the public and the environment against the misuse of nuclear installations and nuclear materials. It consists of a variety of measures against sabotage, theft, and diversion. Measures are usually based on the significance of the protected material or installation. For nuclear safety, the requirements are set by a government authority and are given to the owners or operators of a nuclear installation in the form of an operating license [3].

At the international level, nuclear safeguards are part of the nuclear non-proliferation regime. Since 1970, the field of nuclear safeguards has been the responsibility of the International Atomic Energy Agency (IAEA), a United Nations organization based in Vienna, Austria, of which all EU Member States are members. While the IAEA distinguishes between nuclear-weapon states and nonnuclear-weapon states, the European Commission (EURATOM) inspects all civilian nuclear fuel cycle installations located in the EU [4].

In 1972 the Government of the Socialist Republic of Romania ratified the agreement with the International Atomic Energy Agency on the application of safeguards under the Treaty on the NonProliferation of Nuclear Weapons [5], and in 2000 the Government of Romania concluded with the IAEA an addendum to the same agreement [6].

\section{EXPERIMENTAL}

Nuclear materials represented by natural uranium and thorium salts (Fig. 1) resulted from the activity of taking, transporting, and neutralizing laboratory reagents with expired validity. This laboratory substance management was implemented by SETCAR S.A. Braila, Romania, in the last twenty years.
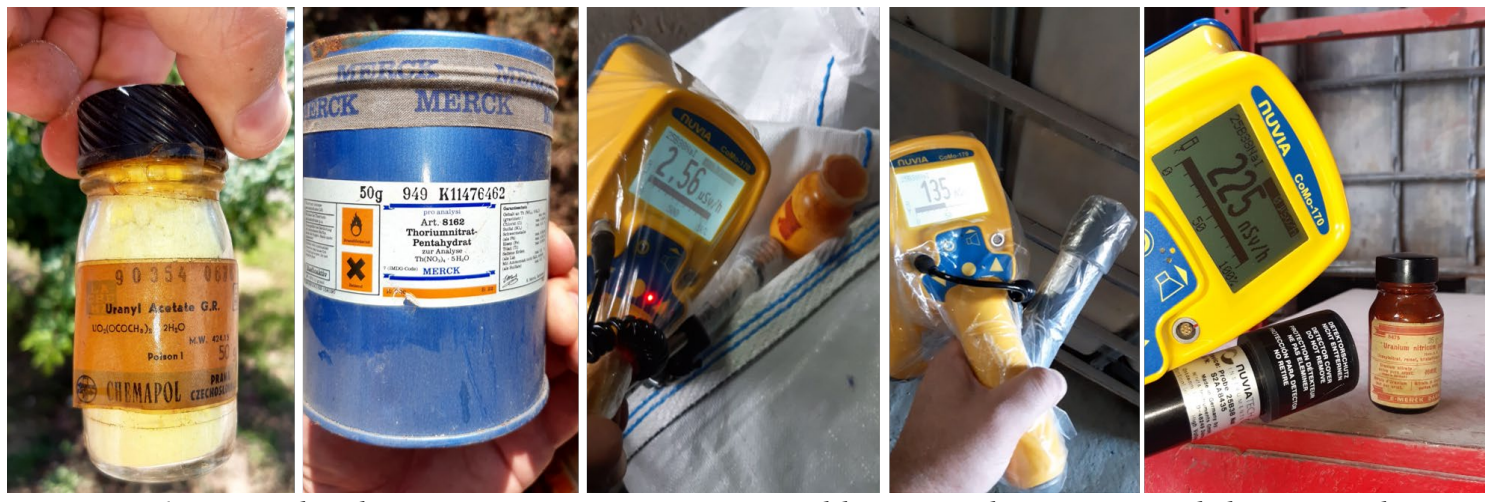

Fig. 1 Expired Laboratory Reagents represented by natural uranium and thorium salts

These nuclear materials have a special regime and must be declared by the National Commission for the Control of Nuclear Activities (CNCAN). Personnel responsible for the management of these materials must be trained and authorized in nuclear practices.

All nuclear materials in the form of laboratory reagents were processed through identification operations according to the manufacturer's label, sorting according to the chemical nature of each substance (Fig. 2), transfer of sorted nuclear materials into new chemically compatible packaging (Fig. 3 ), determining the weight of the respective packaging in order to obtain a value to the nearest third decimal of the mass of each material, the determination by stoichiometric methods of the mass of the nuclear element (U-238 or Th-232) in each object belonging to a batch, and the management of radioactive waste represented by solid objects contaminated with long-lived radionuclides from the radioactive series of U-238 and Th-232 (Fig. 4). 


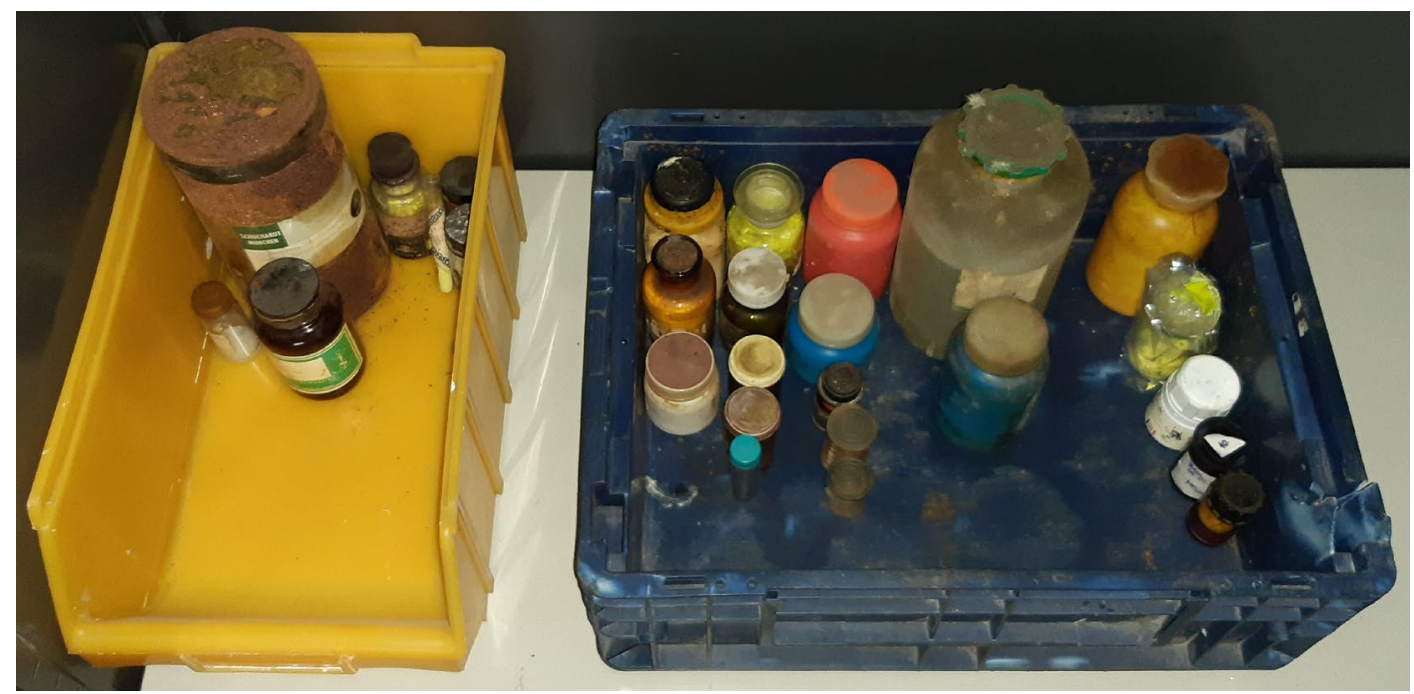

Fig. 2. Sorting the nuclear materials according to chemical structure
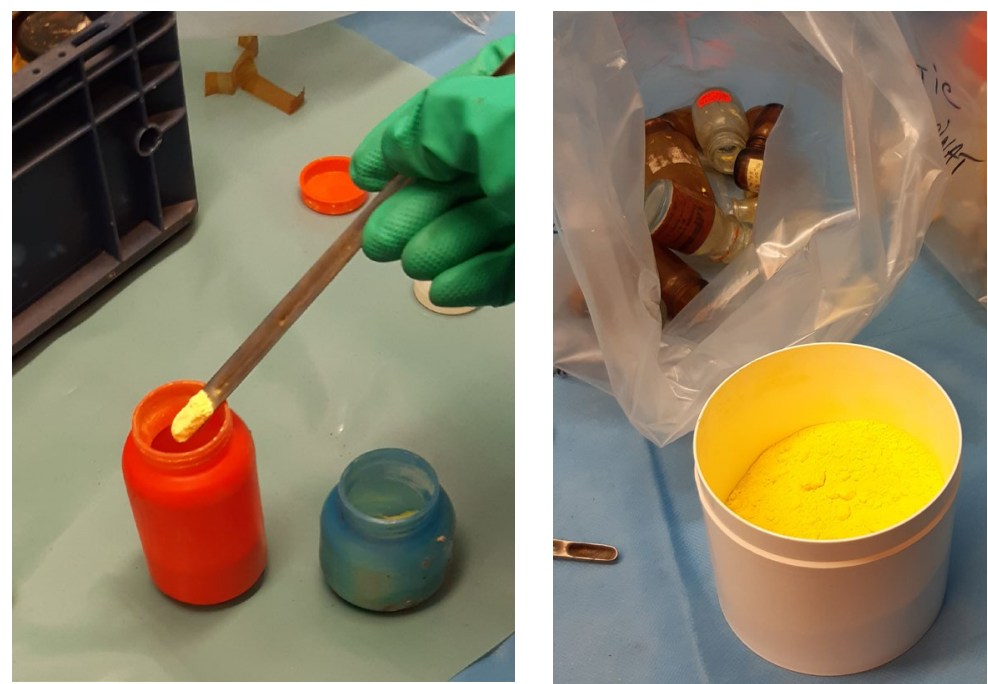

Fig. 3. Repackaging the nuclear materials
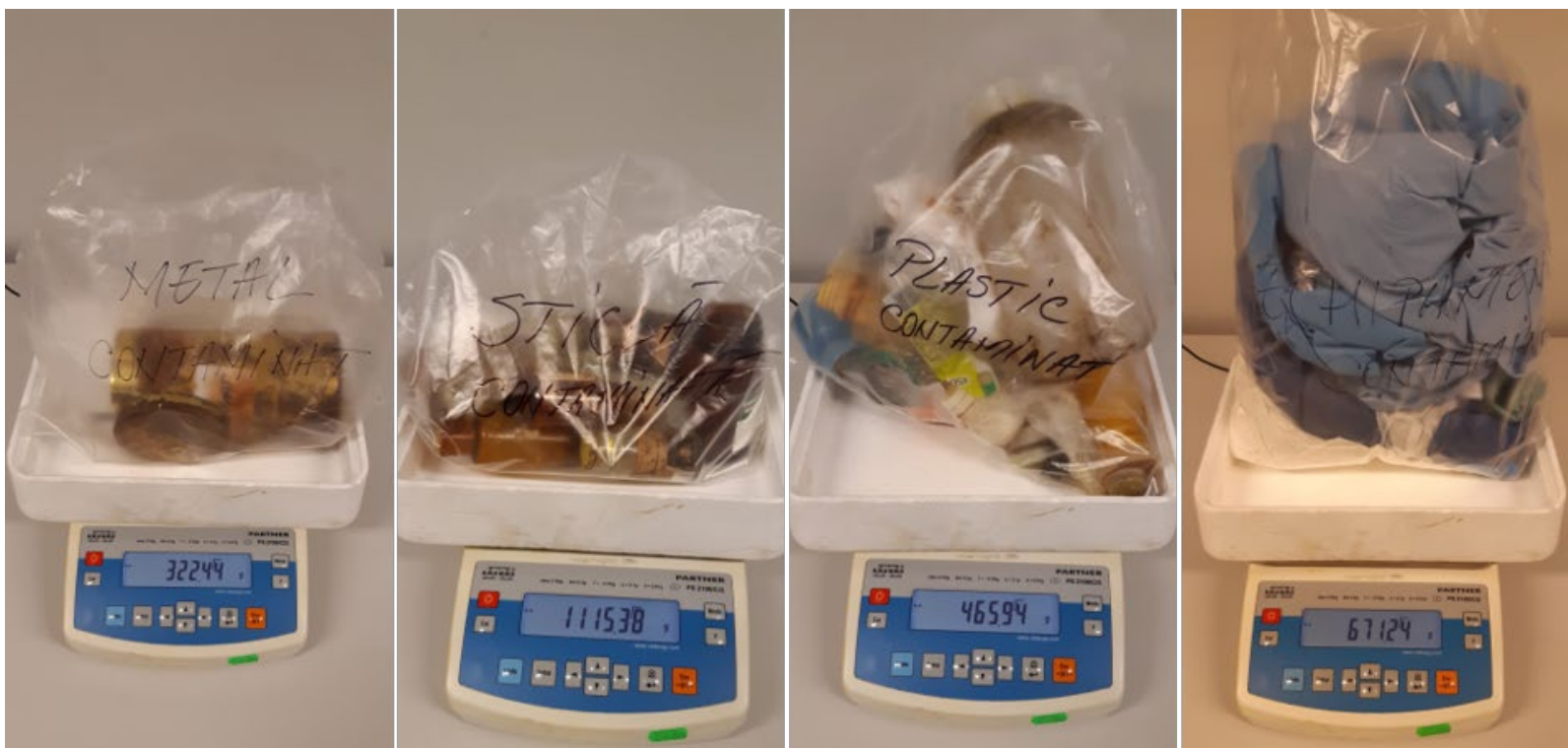

Fig. 4. Sorting and weighing radioactive waste 
All processing steps were performed in accordance with the rules of radiological protection in practices with open sources of ionizing radiation. The personal protective equipment (Fig. 5) against powdery substance containing uranium and thorium salts eligible to use consisted of: overalls for protection against open sources of ionizing radiation, visor, respiratory protection mask with filters against fine particles, chemical resistant gloves, slippers for footwear.
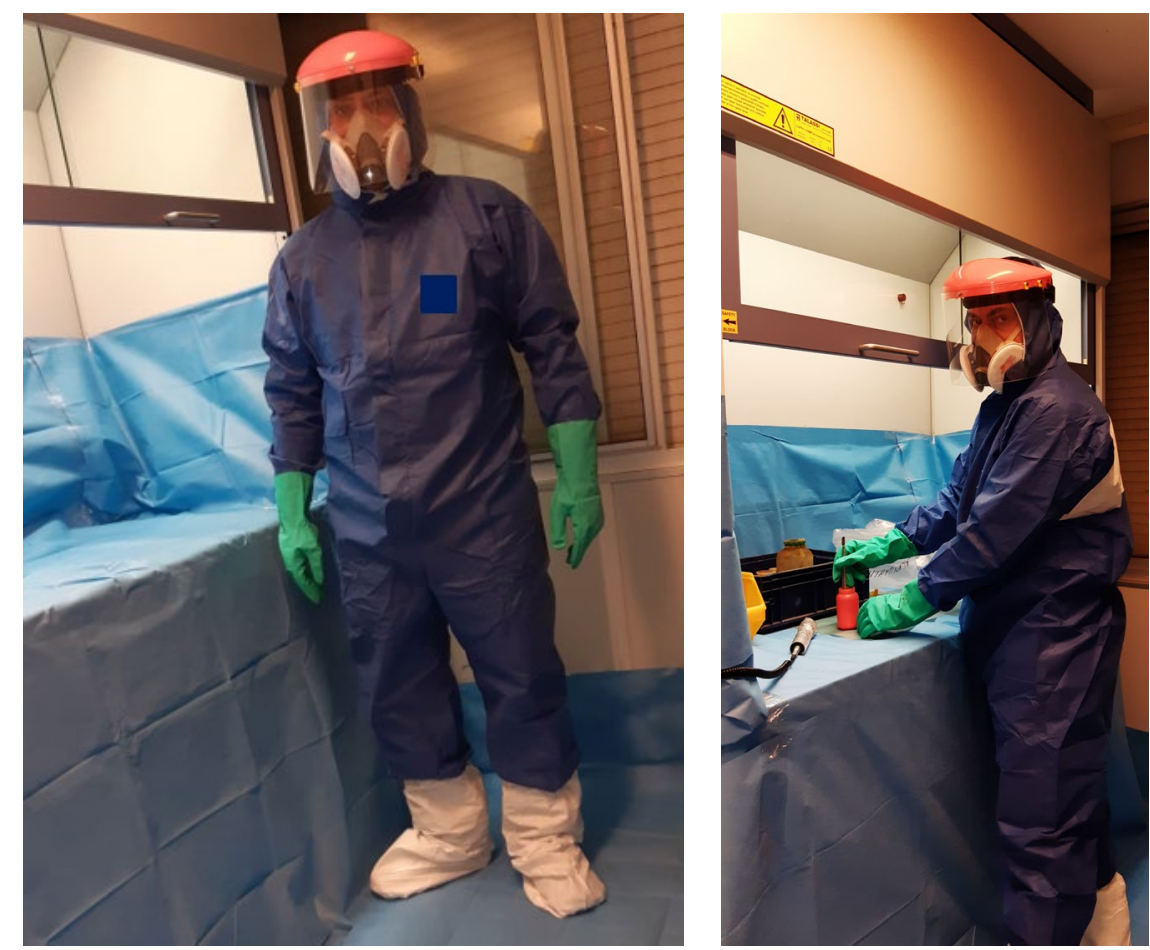

Fig. 5. Personal protective equipment used in the production of open sources of ionizing radiation

In addition to the use of protection against radioactive powdery, methods of protection against ionizing radiation were applied by using individual dosimeters (Fig. 6) [7], measuring gamma dose rate range with approved high performance equipment (Fig. 7), respectively the application of the ALARA principle. The ALARA principle was applied to optimize radiation protection and consisted in limiting the exposure time to ionizing radiation [8].

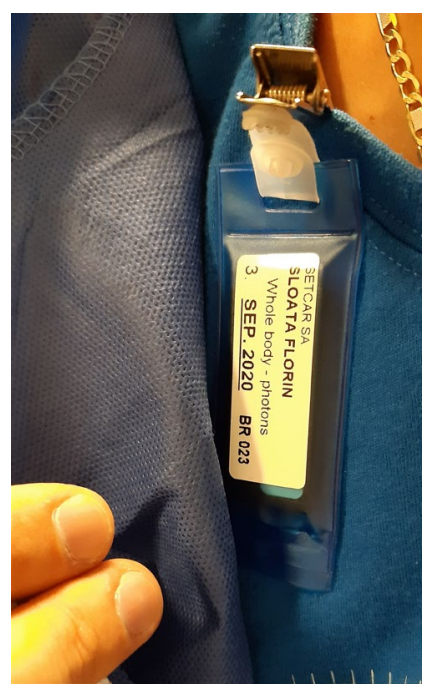

Fig. 6. Dosimeter for individual monitoring of ionizing radiation 


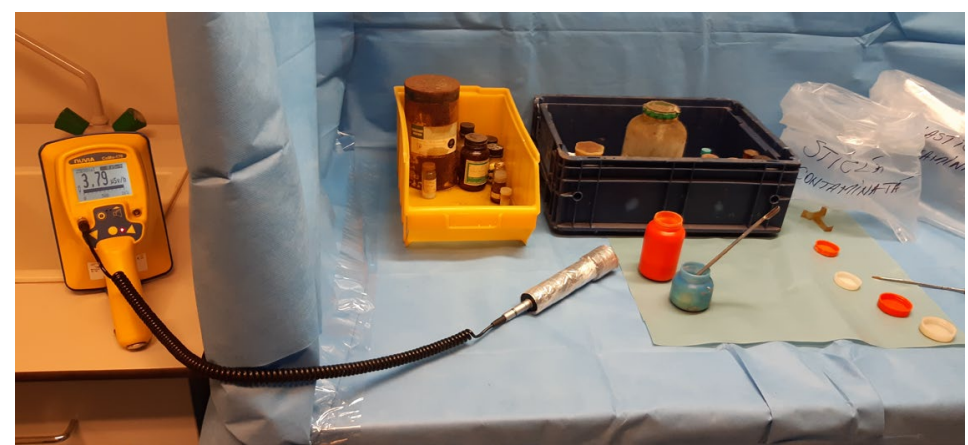

Fig. 7. Monitoring the gamma dose rate with CoMo 170 - Nuvia Instruments

For the correct management and in accordance with international law of nuclear materials, in Table 1 is given the physical inventory that was prepared in which were specified: number of batches, number of objects of the same type in a batch, the name and manufacturer of the chemical, the chemical formula, the form and state of aggregation, material packaging, the mass of nuclear material, the content of element U-238 or Th-232.

Table 1 . The model of physical inventory

\begin{tabular}{|c|c|c|c|c|c|c|c|}
\hline $\begin{array}{l}\text { Safeguard code } \\
\text { (Batch)/ number of } \\
\text { items in batch }\end{array}$ & $\begin{array}{c}\text { Item } \\
\text { number } \\
\text { in batch/ } \\
\text { pack } \\
\text { material }\end{array}$ & $\begin{array}{c}\text { Radiation } \\
\text { source/ } \\
\text { chemical } \\
\text { reagent }\end{array}$ & $\begin{array}{l}\text { Chemical } \\
\text { formula of } \\
\text { nuclear } \\
\text { material }\end{array}$ & $\begin{array}{c}\text { Nuclear } \\
\text { material } \\
\text { form/ } \\
\text { aggregation } \\
\text { state }\end{array}$ & Color & $\begin{array}{c}\text { Nuclear } \\
\text { material } \\
\text { weight } \\
{[\mathrm{g}]}\end{array}$ & $\begin{array}{c}\text { Element/ } \\
\text { element } \\
\text { weight in } \\
\text { the item } \\
{[\mathrm{g}]}\end{array}$ \\
\hline BRSETCARU17/1 & $\begin{array}{l}\text { Item 1/ } \\
\text { pack } \\
\text { HDPE }\end{array}$ & $\begin{array}{c}\text { Uranyl } \\
\text { perchlorate }\end{array}$ & $\begin{array}{c}\mathrm{UO}_{2}\left(\mathrm{ClO}_{4}\right)_{2} \\
6 \mathrm{H}_{2} \mathrm{O}\end{array}$ & $\begin{array}{l}\text { Crystal/ } \\
\text { Solid }\end{array}$ & White & 4.844 & $\begin{array}{c}\text { Natural U/ } \\
2.266\end{array}$ \\
\hline
\end{tabular}

Following the process of sorting, repackaging and weighing all nuclear materials, a number of nine vials were obtained, three of which were known by the manufacturer's label, and six of them were unknown. In addition to the nine vials obtained, a quantity of $2.5 \mathrm{~kg}$ of radioactive waste was represented by solid objects contaminated with U-238 and Th-232 (metal, glass, plastic and contaminated protective equipment). These radioactive wastes were selectively packed in high-density polyethylene bags, then packed in a dedicated high-density polyethylene container with a removable lid and secured with a ring.

For the radionuclide characterization of the six unknown vials and radioactive waste (Figs. 8 and 9), the portable spectrometer Canberra Inspector 1000 was used and equipped with a gamma probe for low background (IPROL-1) that contained a scintillating crystal of lanthanum tribromide [9]. The portable spectrometer is owned by the Nuclear Research Institute of Pitesti, Romania (RATEN $\mathrm{ICN})$.

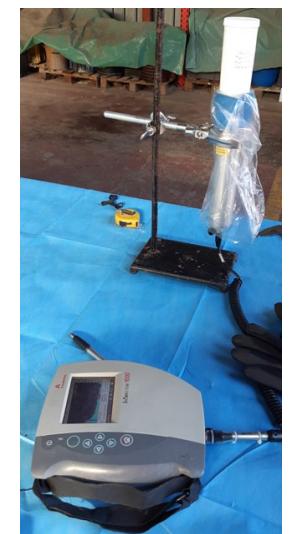

Fig. 8. Measurement of an unknown vial

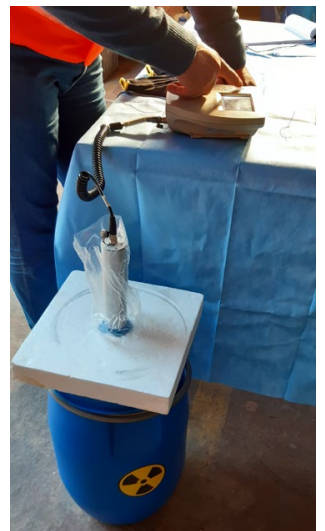

Fig. 9. Measurement of the radioactive waste 
container

The last step for the inventory of nuclear materials and radioactive waste is the labeling of all vials and containers according to the indications specified in the legislation on nuclear safeguards control and the road transport of dangerous goods of Class 7 (ADR). The model labels can be found in Figures 10 and 11.

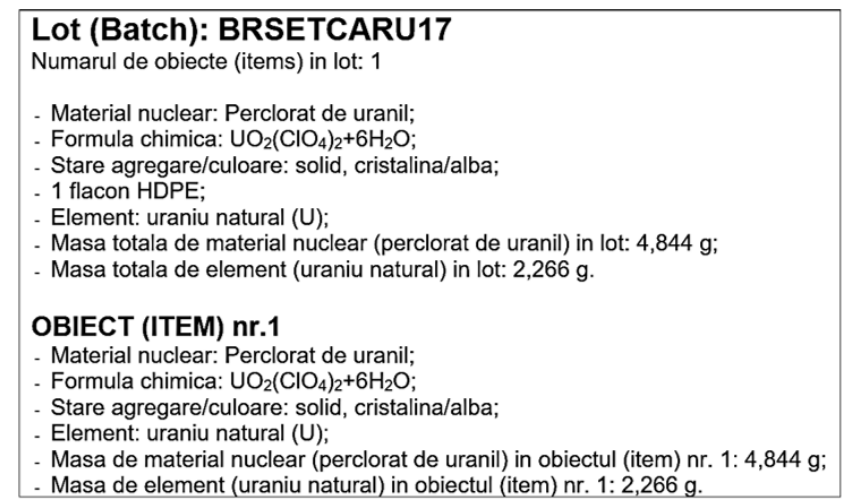

Fig. 10. Label model for nuclear materials

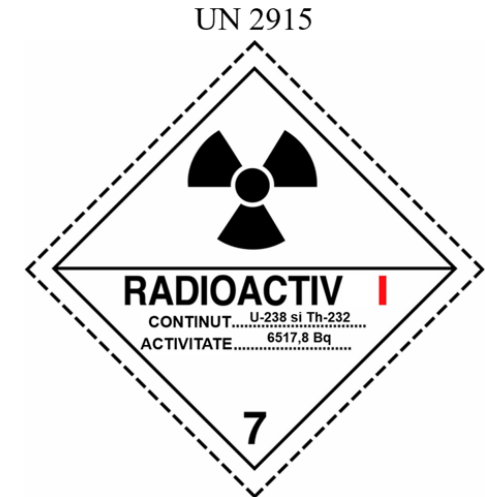

Fig. 11. Label model for radioactive waste

After drawing up the physical inventory, an authorization was requested and obtained for the legal possession of these materials from CNCAN. Intermediate storage of these materials of nuclear interest was only possible with the application of physical protection and safeguards in the nuclear field. Finally, all these nuclear materials were transferred, based on an authorization from CNCAN to an authorized institution in the nuclear field such as RATEN ICN Pitesti, Romania [10], [11].

\section{RESULTS AND DISCUSSION}

The first results were obtained after the completion of the sorting, repackaging, and weighing procedures of all vials containing nuclear materials. These results refer to the degree of contamination with long-lived radionuclides (U-238 and Th-232) of the protective materials of the work surfaces and of the personal protective equipment [12].

The measurements were performed with the CoMo 170 radiometric device produced by Nuvia Instruments Gmbh Germany, equipped with a $170 \times 100 \mathrm{~mm}^{2} \mathrm{PL}$ detector with zinc sulfide calibrated after C-14, Co-60, Cs-137, U-238, Am-241 [13]. measurements.

The values obtained are represented in Table 2, and Figures 12-15 represent images during the

Table 2. Values obtained from measuring superficial radioactive contamination

\begin{tabular}{|lcc|}
\hline \multicolumn{1}{|c}{ Name of the contaminated object } & $\begin{array}{c}\text { The value of superficial } \\
\text { radioactive } \\
\text { contamination }\left(\mathrm{Bq} / \mathrm{cm}^{2}\right)\end{array}$ & $\begin{array}{c}\text { Maximum } \\
\text { allowed limit } \\
\left(\mathrm{Bq} / \mathrm{cm}^{2}\right)\end{array}$ \\
\hline 1. Protective foil on the niche top & 1.65 & \\
2. Protective foil on the walls of the niche & 0.09 & \\
3. Protective foil on the laboratory floor & 0.01 & \\
4. Protective gloves & 0.12 & \\
5. Overalls sleeve & 0.02 & \\
6. The front of the overalls & 0.01 & \\
7. The hood of the overalls & 0 & \\
8. The back of the overalls & 0 & \\
9. Overalls trouser leg & 0 & \\
10. Protective shoes for shoes & 0 & \\
11. Visor & 0 & \\
12. Respiratory protection mask & 0 & \\
\hline
\end{tabular}




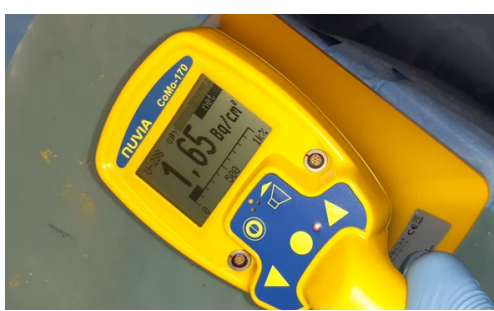

Fig. 12. Measurement of protective foil on the niche top

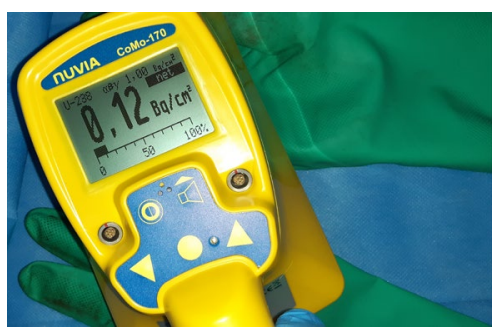

Fig. 14. Measurement of protective gloves

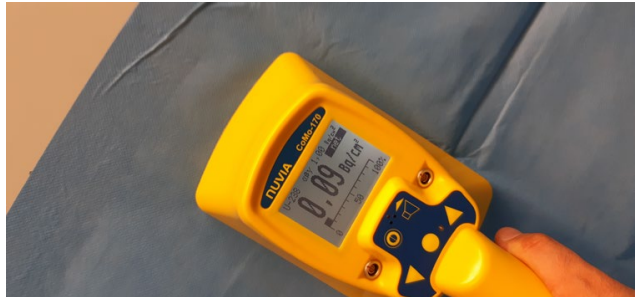

Fig. 13.Measurement of protective foil on the walls of the niche

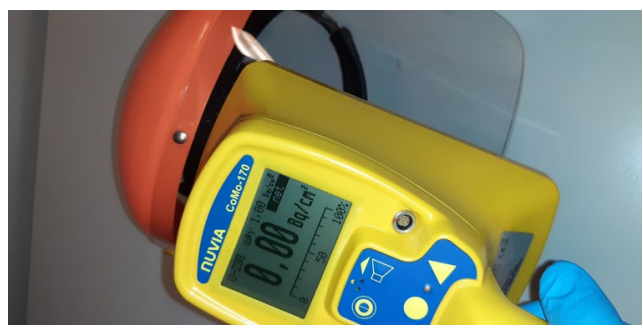

Fig. 15. Measurement of visor

Table 2 shows that a number of twelve objects suspected of contamination with U-238 and Th-232 were measured radiometrically. Following the measurements, a number of 6 contaminated solid objects were identified, the contamination values being in the range of $0.01-1.65 \mathrm{~Bq} / \mathrm{cm}^{2}$. Given that the maximum allowable limit for fixed contamination is $0.05 \mathrm{~Bq} / \mathrm{cm}^{2}$ [14], three of the six contaminated objects were declared radioactive waste. The most contaminated objects were the protective foil of the niche and the protective gloves.

The good application of the ALARA principle for the optimization of radiation protection is confirmed through the results obtained and registered in the dosimetric bulletin no. 126289/29.09.2020, a bulletin that was issued by a CNCAN accredited institution, Dozimed, and that has an individual dosimetry laboratory. The value of the gamma dose (Hp 10) received by the professionally exposed personnel and involved in the handling, repackaging, and labeling of nuclear materials was $0,03 \mathrm{mSv} / \mathrm{month}$, this value is represented in Figure 16. The values of the gamma dose rate (Hp 10) become significant when they exceed $0.17 \mathrm{mSv} / \mathrm{month}$.

The radionuclide characterization of the 6 vials with unidentified radioactive materials and of the container containing solid objects contaminated with U-238 and Th-232 was performed using the Canberra Inspector 1000 portable spectrometer equipped with a gamma probe for low background (IPROL-1) that contained a lanthanum tribromide scintillating crystal. After the characterization was performed, the following results represented in Tables 3 and 4 were obtained.

Table 3. Results obtained after the radionuclide characterization of the six vials containing unidentified radioactive materials

\begin{tabular}{|cccc|}
\hline $\begin{array}{c}\text { Sample } \\
\text { Code }\end{array}$ & $\begin{array}{c}\text { Radionuclide } \\
\text { identified }\end{array}$ & $\begin{array}{c}\text { Mass of } \\
\text { radionuclide }(\mathrm{g})\end{array}$ & $\begin{array}{c}\text { Activity } \\
(\mathrm{kBq})\end{array}$ \\
\hline X1 & $\mathrm{U}-238$ & 20 & 233 \\
X2 & $\mathrm{U}-238$ & 55 & 701 \\
X3 & $\mathrm{U}-238$ & 31 & 464 \\
X4 & $\mathrm{U}-238$ & 0.25 & 3.324 \\
X5 & Th-232 & 0.18 & 727 \\
X6 & Th-232 & 0.16 & 656 \\
\hline
\end{tabular}


Table 4. Results obtained from the radionuclide characterization of the container containing solid objects contaminated with U-238 and Th-232

\begin{tabular}{|ccccc|}
\hline $\begin{array}{c}\text { Sample } \\
\text { Code }\end{array}$ & $\begin{array}{c}\text { Radionuclide } \\
\text { identified }\end{array}$ & $\begin{array}{c}\text { Mass of } \\
\text { radionuclide }(\mathrm{g})\end{array}$ & $\begin{array}{c}\text { Activity } \\
(\mathrm{kBq})\end{array}$ & $\begin{array}{c}\text { Total activity } \\
(\mathrm{kBq})\end{array}$ \\
\hline $\mathrm{C} 1$ & $\mathrm{U}-238$ & 3.70 & 45.7 & 6515.7 \\
\hline
\end{tabular}

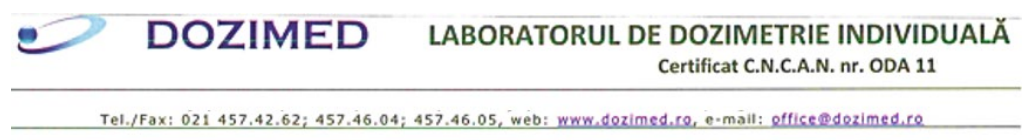

BR 023

Buletin dozimetric Nr.126289/29.09.2020

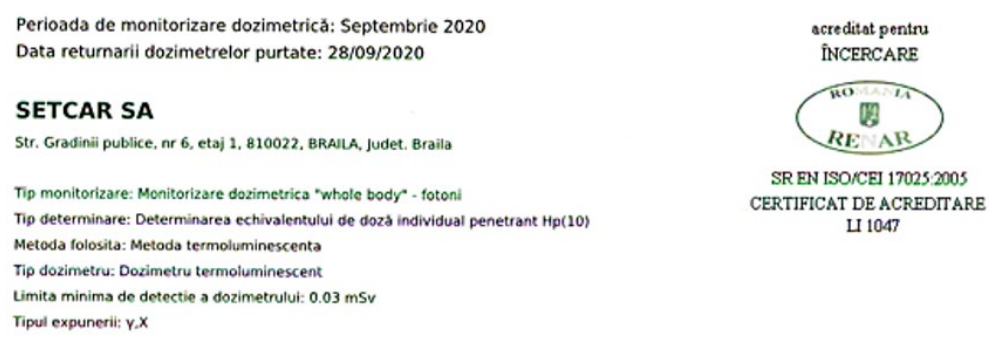

\begin{tabular}{|c|c|c|c|c|c|}
\hline $\begin{array}{l}\text { Nr. } \\
\text { crt. }\end{array}$ & CNP & Numele și prenumele & Doximetru & $\begin{array}{l}\text { Hp(10) } \\
\text { mSv }\end{array}$ & Observații \\
\hline 1 & 1 & & 0499939 & 0.03 & \\
\hline 2 & 3 & & 0504369 & 0.03 & \\
\hline 3 & 8 & SLOATA FLORIN & 0512243 & 0.03 & \\
\hline 4 & 1 & & 0523940 & 0.03 & \\
\hline
\end{tabular}

Fig. 16. The results obtained for September 2020 according to the dosimetric bulletin

As can be seen from Tables 3 and 4, the six unknown vials containing radioactive materials were named $\mathrm{X}$ from one to six. The container containing radioactive wastes contaminated by solid objects represented by the long-lived radionuclides from the radioactive series of U-238 and Th-232 was named $\mathrm{C} 1$.

In the first four vials, the presence of U-238 was identified with a weight between 0.25 and 55 $\mathrm{g}$, and the specific activity has values between 3.324 and $701 \mathrm{kBq}$. In the last two vials, the presence of Th-232 was identified with a weight between 0,16 and $0,18 \mathrm{~g}$, and the values of the specific activity were in the range $656-727 \mathrm{kBq}$.

About the container containing radioactive waste represented by solid objects contaminated with U-238 and Th-232, it can be said that they have identified the presence of U-238 and Th-232 respectively. The mass of $\mathrm{U}-238$ is $3.70 \mathrm{~g}$ as opposed to Th-232 which is $1.59 \mathrm{~g}$. Even if the mass of $\mathrm{U}-238$ is greater than the mass of Th-232, it has a specific activity of $45.7 \mathrm{kBq}$ compared to $6470 \mathrm{kBq}$.

\section{CONCLUSIONS}

Declaring nuclear materials is strictly necessary to respect international norms on nuclear safeguards. In addition to the fact that these substances are nuclear materials, they are chemicals with high toxicity, but also long-live radioactive substances.

It is very important to protect against open radiation sources to avoid internal contamination of the human body, contamination that is more harmful than external exposure to ionizing radiation.

In this experimental program, the ALARA principle was applied by significantly reducing the exposure to ionizing radiation. This fact is proved by the values recorded in the dosimetric bulletin.

Nuclear spectrometric methods applied in situ are effective in detecting radionuclides in an unknown sample, their mass, and nuclear activity. 
Even if they have been applied very carefully the handling and repackaging of radioactive/nuclear materials, following measurements to determine suspicious contamination, the presence of U-238 and Th-232 was identified in some solid objects. All the contaminated objects were declared as radioactive waste and managed according to CNCAN laws.

\section{Acknowledgment}

The authors acknowledge the support from the project BSB-MONITOX financed by the Joint Operational Programme Black Sea Basin 2014-2020.

\section{REFERENCES}

1. L.K. Mansur, Comprehensive Nuclear Materials, 13, 2011.

2. D.C. Hall, Encyclopedia of Energy, 657, 2004.

3. D. Schriefer, Safeguards, security, safety and the nuclear fuel cycle, In: Woodhead Publishing Series in Energy, Nuclear Fuel Cycle Science and Engineering (Editor: Ian Crossland), Woodhead Publishing, 2012, pp. 52-79, ISBN 9780857090737, https://doi.org/10.1533/9780857096388.1.52.

4. European Commission, Nuclear Safeguards, 6, 2014.

5. http://www.cncan.ro/assets/Informatii-Publice/07-Documente-necesare-pentruautorizare/Garantii-nucleare/01-acordgarantii.pdf

6. http://www.cncan.ro/assets/Informatii-Publice/07-Documente-necesare-pentruautorizare/Garantii-Nucleare/02-protacord01.pdf

7. Order of the CNCAN President no. 14/2401.2000, Fundamental norms of radiological safety, art. 55, 7, 2000.

8. Order of the CNCAN President no. 14/2401.2000, Fundamental norms of radiological safety, art. 16, 7, 2000.

9. http://www.old.slcj.uw.edu.pl/ agniecha/por/InSpector100UserManual.pdf

10. Order of the CNCAN President no. 382/24.10.2001, Norms of physical protection in the nuclear field, art. 14-37, 3-4, 2001.

11. Order of the CNCAN President no. 363/14.09.10.2001, Norms of safeguards in nuclear field, art. 98, 9, 2001.

12. Order of the CNCAN President no. 192 / 26.09.2002, Radiological safety norms regarding the management of radioactive waste from the mining and preparation of uranium and thorium ores, art. 7, 2, 2002.

13. https://www.nuviatech-healthcare.com/wp-content/uploads/sites/2/2017/10/NVG-375060 Fichesx6Corr-CoMo-Aout2020-V3-1.pdf.

14. Order of the CNCAN President no. 207/24.11.2003, Radiological safety rules regarding the decommissioning of installations mining and/or preparation of uranium and/or torium ore criteria for release under the CNCAN authorization regime for use of buildings, materials, installations for other purposes, dumps and land contaminated by mining activities and/or preparation of uranium and/or thorium ore, art. 73, 12, 2003. 